\title{
Paternalism in mental health: time for rehabilitation? Tom Burns
}

\author{
Address: University of Oxford, Warneford Hospital, Oxford, OX3 7JZ, UK \\ from WPA Thematic Conference. Coercive Treatment in Psychiatry: A Comprehensive Review \\ Dresden, Germany. 6-8 June 2007 \\ Published: 19 December 2007 \\ BMC Psychiatry 2007, 7(Suppl I):S23 doi:10.1 186/I47I-244X-7-SI-S23
}

This abstract is available from: http://www.biomedcentral.com/ I 47I-244X/7/SI/S23

(C) 2007 Burns; licensee BioMed Central Ltd.

Mental health legislation has received enormous attention internationally in the era of deinstitutionalization, particularly as societies become more risk averse. The response has been framed within a libertarian tradition and the language is almost exclusively about autonomy and partnership. Apart from risk, patient autonomy has gone from being one of the principles in the discourse surrounding mental health legislation to being the principle one. Paternalism and beneficence are discarded as discredited. Practice, however, is still recognisably paternalistic in most developed countries. This disjunction between the public language and common practice leads to sometimes tortured and unconvincing definitions (to permit current practice) and unhelpful confusion in the public mind about what psychiatry is. Contrary to the widespread belief within mental health that everyone else has abandoned paternalism there are cogent and respectable critiques of autonomy as a dominant ethical principle. These critiques encourage a less damning view of paternalism seeking to place it alongside other ethical goals in society. These challenges come from within economics, the law, political philosophy and, perhaps most surprisingly, from some feminist authors. These critiques will be briefly outlined with the modest ambition of encouraging debate in this area. While patient autonomy is important it does not preclude the legitimate consideration of restriction of liberty in a patient's best interests. A debate which reflects more accurately what we do (rather than think we ought to do) may be more helpful in informing policy and legislation. 